\title{
Photovoltaic conversion and quantum efficiency in perovskite multiferroic ceramics
}

\author{
Authors: Chi-Shun Tun, Pin-Yi Chen, Cheng-Sao Chen, R. \\ R. Chien, V. Hugo Schmidt, and Chun-Yen Lin
}

NOTICE: this is the author's version of a work that was accepted for publication in Acta Materialia. Changes resulting from the publishing process, such as peer review, editing, corrections, structural formatting, and other quality control mechanisms may not be reflected in this document. Changes may have been made to this work since it was submitted for publication. A definitive version was subsequently published in Acta Materialia, vol. 149, May 2018, DOI\#10.1016/j.actamat.2018.02.043

Tu, Chi-Shun, Pin-Yi Chen, Cheng-Sao Chen, R. R. Chien, Hugo V. Schmidt, and Chun-Yen Lin. "Photovoltaic conversion and quantum efficiency in perovskite multiferroic ceramics." Acta Materialia 149 (May 2018): 248-255. DOI: 10.1016/j.actamat.2018.02.043.

Made available through Montana State University's $\underline{\text { ScholarWorks }}$ scholarworks. montana.edu 


\title{
Photovoltaic conversion and quantum efficiency in perovskite multiferroic ceramics
}

\author{
Chi-Shun Tu ${ }^{\text {a }}$, Pin-Yi Chen ${ }^{\mathrm{b}}$, Cheng-Sao Chen ${ }^{\mathrm{c}}$, R.R. Chien ${ }^{\mathrm{d}}$, V. Hugo Schmidt ${ }^{\mathrm{d}}$, \\ Chun-Yen Lin ${ }^{\text {a }}$ \\ a Department of Physics, Fu Jen Catholic University, New Taipei City 24205, Taiwan \\ b Department of Mechanical Engineering, Ming Chi University of Technology, New Taipei City 24301, Taiwan \\ ${ }^{\mathrm{c}}$ Department of Mechanical Engineering, Hwa Hsia University of Technology, New Taipei City 23567, Taiwan \\ d Department of Physics, Montana State University, Bozeman, MT 59717, USA
}

\begin{abstract}
A B S T R A C T
Junction-driven photovoltaic effects in lead-free perovskite $\mathrm{BiFeO}_{3}$ multiferroic materials have demonstrated promising applications in energy harvesting and optical sensors. This study highlights remarkable photon-to-electron external quantum efficiency (EQE) of $\sim 9 \%$ and light-to-electric power-conversion efficiency (PCE) of $\sim 0.8 \%$ in the heterostructure consisting of A-site neodymium-doped $\mathrm{BiFeO}_{3}$ ceramic and indium-tin-oxide (ITO) thin film under irradiation of wavelength $\lambda=405 \mathrm{~nm}$. A theoretical p-njunction model based on the photo-generated carriers was employed to quantitatively describe opencircuit voltage $\left(\mathrm{V}_{\mathrm{oc}}\right)$ and short-circuit current density $\left(\mathrm{J}_{\mathrm{sc}}\right)$ as functions of irradiation intensity, and to calculate junction widths and carrier densities. The direct band gap and the degree of local disorder (or defect state) were estimated using the photon-energy-dependent optical attenuation coefficient with the Tauc and Urbach relations.
\end{abstract}

\section{Introduction}

Photovoltaic (PV) effects in non-centrosymmetric polar perovskite oxides have attracted much attention in recent years for potential applications of solar energy harvesting [1-4]. The bulk photovoltaic effect (BPVE) has been observed in perovskite ferroelectric (FE)/piezoelectric oxides which lack a center of inversion symmetry, such as $\mathrm{LiNbO}_{3}$ [5,6], $\mathrm{BaTiO}_{3}$ [7], $\mathrm{Pb}(\mathrm{Zr}, \mathrm{Ti}) \mathrm{O}_{3}$ (PZT) [8-14], (Pb,La)(Zr,Ti)O 3 [15-17], $\mathrm{KNbO}_{3}-\mathrm{Ba}\left(\mathrm{Ni}_{1 / 2} \mathrm{Nb}_{1 / 2}\right) \mathrm{O}_{3}$ [18], and tungsten-doped $\mathrm{Pb}\left(\mathrm{Mg}_{1 / 3} \mathrm{Nb}_{2 / 3}\right)_{1-\chi} \mathrm{Ti}_{x} \mathrm{O}_{3}$ (PMN-PT) crystals [19]. Two mechanisms have been proposed to account for the BPVE phenomena, including ballistic and shift mechanisms $[3,4,20]$. The ballistic mechanism is associated with the asymmetric momentum distribution of non-thermalized carriers [20]. The shift mechanism is attributed to the non-diagonal elements of the density matrix, in which the BPVE is caused by the shift $(\bar{R})$ in the material following the band-band transition [2]. The linear BPVE current density is expressed by the relation $\mathrm{j}_{B P V E}^{\mathrm{i}}=\alpha g_{i j l} e_{j} e_{l} I_{0}$, where $\alpha$ is the absorption coefficient, $e_{j}$ and $e_{l}$ are the components of light polarization, $g_{i j l}$ is the third-rank piezoelectric tensor, and $I_{o}$ is the light intensity [4].

The photocurrent densities of most FE materials are however only of order $10^{-2}-10^{-5} \mathrm{~A} / \mathrm{m}^{2}$ due to wide optical band gaps (typically 3-4 eV) [5-19]. Enhanced PV power-conversion efficiencies (from $10^{-4}$ to $\sim 0.5 \%$ ) have been achieved recently by tailoring layer thickness, poling electric field, domain structures, electrode-ferroelectric interface, and band gap [16-19,21]. For example, the $\left(\mathrm{La}_{0.7} \mathrm{Sr}_{0.3}\right) \mathrm{MnO}_{3} /\left(\mathrm{Pb}_{0.97} \mathrm{La}_{0.03}\right)\left(\mathrm{Zr}_{0.52} \mathrm{Ti}_{0.48}\right) \mathrm{O}_{3} / \mathrm{Nb}-$ $\mathrm{SrTiO}_{3}$ heterostructure exhibited a maximal power-conversion efficiency (PCE) of $0.28 \%$ under ultraviolet irradiation (photon energy $=3.5 \mathrm{eV}$ ) [16]. A first-principles calculation proposed that the band gap $\left(E_{\mathrm{g}}\right)$ depends on structure in perovskite ferroelectrics, for instance $E_{\mathrm{g}}=2.3 \mathrm{eV}$ and $E_{\mathrm{g}}=1.74 \mathrm{eV}$ in $\mathrm{BaTiO}_{3}$ for rhombohedral and tetragonal phases, respectively [22]. A high PCE $(\sim 4.8 \%)$ at nanoscale distances was obtained recently from a (001) $\mathrm{BaTiO}_{3}$ single crystal under 1 sun $\left(1000 \mathrm{~W} / \mathrm{m}^{2}\right)$ AM1.5G irradiance by using an atomic force microscope (AFM) tip [4]. It has been demonstrated that the high PCE can be achieved within a free path $\left(l_{0}\right)$, which is estimated to be from tens to hundreds of nanometers [4].

Photovoltaic phenomena in lead-free multiferroic $\mathrm{BiFeO}_{3}$ (BFO) with various electrodes have been explored intensively in recent years [23-44]. Several mechanisms have been proposed for the PV 
effects, including the asymmetric ferroelectric PV effect (or BPVE) [11,29], the domain-wall model [30], and the p-n junction model $[39,40]$. The Pt/BFO single crystal/Pt heterostructure showed an open-circuit voltage $\mathrm{V}_{\mathrm{oc}} \sim 13 \mathrm{~V}$ and a short-circuit current density $\mathrm{J}_{\mathrm{sc}} \sim 0.01 \mathrm{~A} / \mathrm{m}^{2}$ under irradiation of $\lambda=405 \mathrm{~nm}$ [35]. The open-circuit voltage in $\mathrm{Pt} / \mathrm{BFO} / \mathrm{TbScO}_{3}$ thin films can reach $\mathrm{V}_{\text {oc }} \sim 50 \mathrm{~V}$ under irradiation of $\lambda=405 \mathrm{~nm}$ by controlling the conductivities along domain walls [37]. An external quantum efficiency (EQE) of $10 \%$ under irradiation of $\lambda=340 \mathrm{~nm}$ was reported in $\mathrm{ITO} / \mathrm{BFO} / \mathrm{SrRuO}_{3}$ thin films [39]. Substantial PV effects have been reported recently in a heterostructure consisting of a p-type rare-earth $(R E)$ substituted $\mathrm{BiFeO}_{3}$ and an n-type ITO thin film (top electrode) [41-44]. An ITO/BFO5Sm ceramic/Au heterostructure exhibited a maximal PCE of $\sim 0.37 \%$ and an $\mathrm{EQE}$ of $\sim 4.1 \%$ respectively under irradiation of $\lambda=405 \mathrm{~nm}$ [42]. A theoretical p-n-junction-like model based on photo-generated current in the depletion region between the BFO ceramics and the ITO thin film was developed to describe $V_{o c}$ and $J_{s c}$ as functions of irradiation intensity $[40,42]$. The direct band gaps of $\left(\mathrm{Bi}_{1-\mathrm{x}} \mathrm{Sm}_{\mathrm{x}}\right) \mathrm{FeO}_{3}$ ceramics vary from $2.24 \mathrm{eV}$ in BFO to $2.15 \mathrm{eV}$ in $\left(\mathrm{Bi}_{0.9} \mathrm{Sm}_{0.1}\right) \mathrm{FeO}_{3}$ (BFO10Sm) [42]. This is consistent with the first-principles-calculated band gap of $\sim 2.25 \mathrm{eV}$ in BFO ceramic [41]. It was suggested that microstructures and atomic orbital hybridizations (between $\mathrm{O} 2 p$ and $\mathrm{Fe} 3 d / \mathrm{Bi}$ 6sp orbital states) play important roles for the PV responses as photo-generated carriers travel through ceramic matrix [42].

A structural transition from a ferroelectric rhombohedral $R 3 c$ to a nonpolar orthorhombic Pnma structure was proposed upon heating in $\left(\mathrm{Bi}_{1-\chi} R E_{\chi}\right) \mathrm{FeO}_{3}$ based on average A-site ionic radii [45]. The XRD and TEM studies revealed a rhombohedral $R 3 C$ phase in $\left(\mathrm{Bi}_{1-x} \mathrm{Nd}_{x}\right) \mathrm{FeO}_{3}$ ceramics for $0 \leq x \leq 0.1[46,47]$. Our previous study in $\left(\mathrm{Bi}_{1-x} \mathrm{Nd}_{x}\right) \mathrm{FeO}_{3}(0 \leq x \leq 0.10)$ ceramics suggests that A-site $\mathrm{Nd}$ substitution decreases hybridizations of the $\mathrm{O} 2 p$-Fe $3 d$ and the $\mathrm{O}$ $2 p$-Bi $6 s p$ orbitals [47]. In this work, we focus on effects of A-site Nd substitution on PV properties in ITO/BF100xNd ceramics/Au heterostructures under near-ultraviolet irradiation $(\lambda=405 \mathrm{~nm})$. The influences of optical band gap and microstructure in PV responses are explored as functions of $\mathrm{Nd}$ concentration. A p-n-junction model based on the photo-generated carriers was employed to quantitatively describe the open-circuit voltage $\left(\mathrm{V}_{\mathrm{oc}}\right)$ and shortcircuit current density $\left(\mathrm{J}_{\mathrm{sc}}\right)$ as functions of irradiation intensity.

\section{Experimental procedure}

$\left(\mathrm{Bi}_{1-x} \mathrm{Nd}_{x}\right) \mathrm{FeO}_{3}(x=0.03-0.10)$ ceramics were prepared by the solid state reaction, in which $\mathrm{Bi}_{2} \mathrm{O}_{3}, \mathrm{Nd}_{2} \mathrm{O}_{3}$, and $\mathrm{Fe}_{2} \mathrm{O}_{3}$ powders (purity $\geq 99.0 \%$ ) were weighed in the stoichiometric ratios. Hereafter, BFO3Nd, BFO5Nd, BFO7Nd, and BFO10Nd represent compositions of $x=0.03,0.05,0.07$, and 0.10 , respectively. The powders were mixed in an agate mortar with alcohol as milling medium for more than $72 \mathrm{~h}$ and then were calcined at $800^{\circ} \mathrm{C}$ for $3 \mathrm{~h}$. The sintering temperatures are respectively $850,870,890$, and $890^{\circ} \mathrm{C}$ $($ dwell time $=3 \mathrm{~h}$ ) for BFO3Nd, BFO5Nd, BFO7Nd, and BFO10Nd. Average grain sizes are respectively $5.4,4.5,4.3$, and $4.2 \mu \mathrm{m}$ for BFO3Nd, BFO5Nd, BFO7Nd, and BFO10Nd [47]. The optical transmission spectra were measured by using a Cary 5E UV-Vis-NIR spectrometer. A high-resolution transmission electron microscope (HRTEM, JEOL JEM-2100 $\mathrm{LaB}_{6}$ ) with an accelerating voltage of $200 \mathrm{kV}$ was used to analyze microstructures and diffraction patterns.

For photovoltaic effects, indium tin oxide (ITO) and Au thin films were deposited on the ceramic surfaces as top and bottom electrodes respectively by sputtering depositions. The irradiated area (also electrodes area) of as-sintered specimens is about $0.15 \mathrm{~cm}^{2}$. The ceramic samples were not poled by a dc electric field before the photovoltaic measurements. A diode laser beam of wavelength $\lambda=405 \mathrm{~nm}$ was used as the irradiation source and was incident perpendicularly on the ITO surface. The optical transmission of ITO thin film is about $80 \%$ at wavelength $\lambda=405 \mathrm{~nm}$ [41]. For powerconversion efficiency (PCE), an adjustable load resistance $\left(\mathrm{R}_{\mathrm{L}}\right)$ was used to obtain curves of load current density $\left(\mathrm{J}_{\mathrm{L}}\right)$ vs. load voltage $\left(V_{L}\right)$ under irradiation. The light-to-electric power-conversion efficiency (PCE) is calculated by using the equation, $P C E=P_{\text {out }} / P_{\text {in }}$, where $P_{\text {out }}=J_{L} \cdot V_{L}$ is the output electric power density $\left(\mathrm{W} / \mathrm{m}^{2}\right)$ across the load and $P_{\text {in }}$ is the irradiation intensity $\left(\mathrm{W} / \mathrm{m}^{2}\right)$ measured on the ITO surface.

\section{Results and discussion}

Fig. 1 shows curves of optical transmission $(\mathrm{T}), \ln (\alpha)$, and $(\alpha h \nu)^{2}$ vs. photon energy $(h v) . \alpha, h$, and $v$ are absorption coefficient, Planck's constant, and photon frequency, respectively. The specimens for optical transmission measurements were polished to a few micrometers as illustrated in the inset of Fig. 1(a). The specimen thicknesses were determined by using a Hitachi S-3400N scanning electron microscope (SEM) and are about $9.3,7.4,7.3$, and $7.4 \mu \mathrm{m}$ for BFO3Nd, BFO5Nd, BFO7Nd, and BFO10Nd, respectively. The

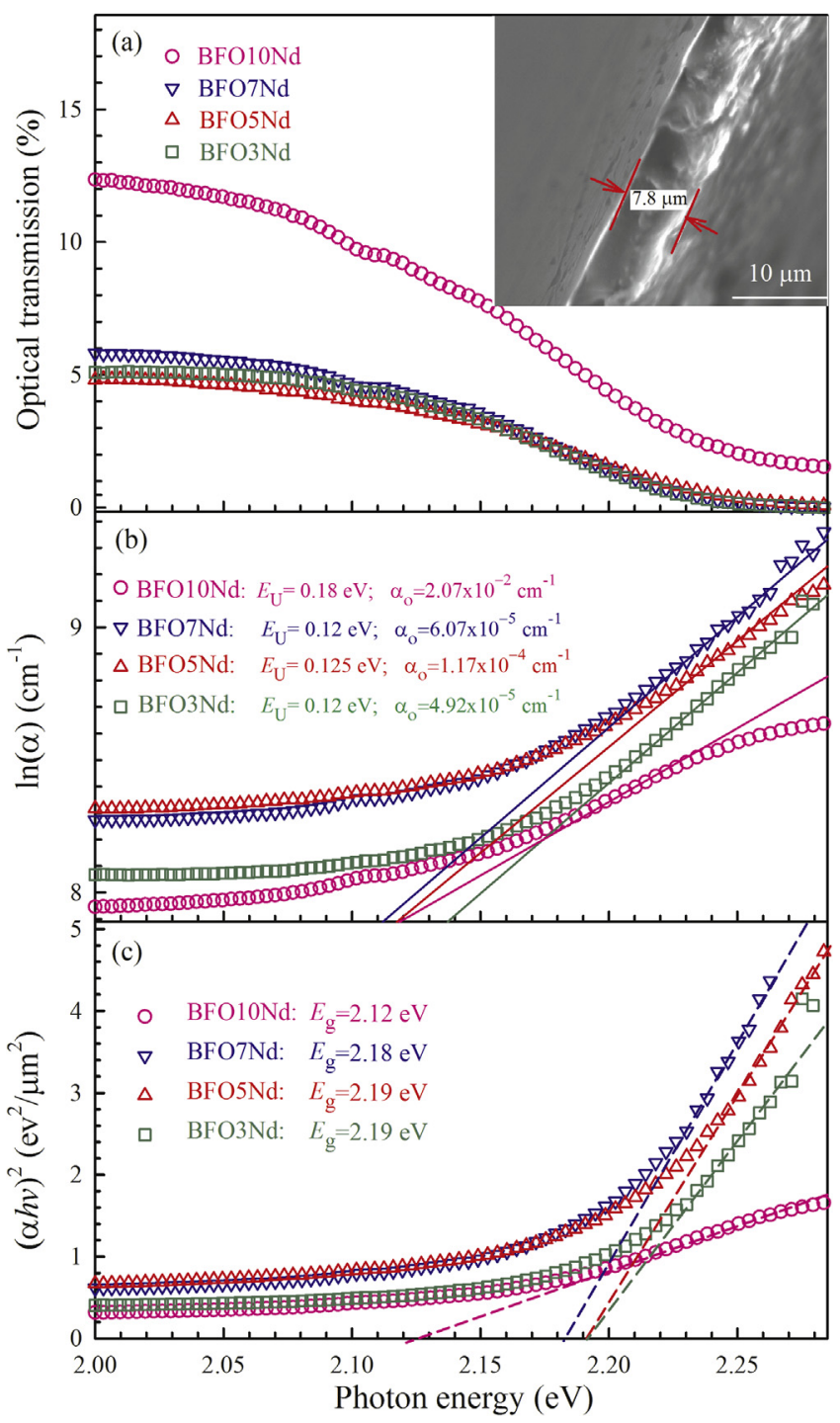

Fig. 1. (a) Optical transmission, (b) $\ln (\alpha)$, and (c) $(\alpha h \nu)^{2}$ vs. photon energy. The inset in (a) is an illustration of the specimen used for transmission measurement. 
correlation between the optical transmission $\mathrm{T}$ and absorption coefficient $\alpha$ can be expressed by Ref. [48],

$\mathrm{T}=\left(1-R^{2}\right) e^{-\alpha \mathrm{d}}$

where $\mathrm{R}$ and $\mathrm{d}$ are the optical reflectivity and specimen thickness, respectively. In this study, we assume the reflectivity to be negligible, i.e. $\alpha=-\ln (\mathrm{T}) / d$.

To analyze the effects of defects and degree of local disorder on the optical absorption behavior, the curves of $\ln (\alpha)$ vs. photon energy are plotted in Fig. 1(b). The linear regions near the band edges can be described by the Urbach relation [48], i.e.

$\alpha=\alpha_{0} e^{h v / E_{U}}$

where $\alpha_{0}$ and $E_{\mathrm{U}}$ are the characteristic parameter and Urbach energy. The solid lines in Fig. 1(b) are fits of Eq. (2) with parameters in Fig. 1(b). BFO10Nd has an apparently larger Urbach energy than the other three compositions. The $E_{\mathrm{U}}$ corresponds to the width of tail states near the absorption-band edge and is associated with the structural defects and disordering in the materials, which can result in sub-band defect states between conduction and valence bands. Fig. 1(c) shows the plots of $(\alpha h v)^{2}$ vs. photon energy $(h v)$. The direct optical band gap $\left(E_{\mathrm{g}}\right)$ can be estimated using the Tauc relation [48], $(\alpha h v)^{2}=A\left(h v-E_{g}\right)$, by extrapolating the straight lines as indicated by the dashed lines in Fig. 1(c). The optical band gaps $\left(E_{\mathrm{g}}\right)$ decrease from $2.19 \mathrm{eV}$ in BFO3Nd to $2.12 \mathrm{eV}$ in BFO10Nd. The significant reduction of band gap in BFO10Nd can result from intrinsic defects and is consistent with the larger Urbach energy $\left(E_{\mathrm{U}}\right)$ in BFO10Nd as shown in Fig. 1(b). It was reported that the optical band gap also depends on electronic bond, grain size, and impurity phase $[48,49]$.

To study microstructure and lattice defects, high-resolution TEM was used to obtain nanoscale lattice structures and diffraction patterns. Fig. 2(a) shows TEM bright-field images (BFI) in BFO5Nd. Fig. 2(b) is the enlargement from the red rectangle indicated in Fig. 2(a) and reveals some high-strain regions with local lattice distortion. Fig. 2(c)-(f) are selected area diffraction patterns (SADPs) along the [100], [110], [111], and [112]-zone axes with $1 / 2$ (ooo) superlattice diffractions from a number of grains in the BFO5Nd

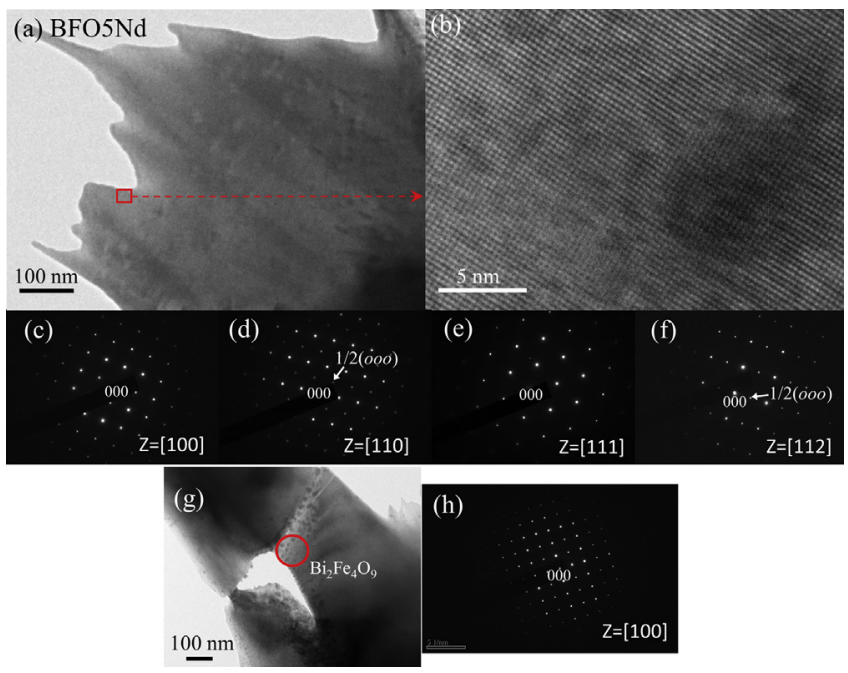

Fig. 2. (a) TEM bright-field image (BFI), (b) high-resolution lattice image from the red rectangle in (a), and (c)-(f) SADPs from a number of grains in the BFO5Nd ceramic matrix. (g) $\mathrm{Bi}_{2} \mathrm{Fe}_{4} \mathrm{O}_{9}$ impurity phase as indicated by the circle and (h) its SADP. (For interpretation of the references to colour in this figure legend, the reader is referred to the Web version of this article.) ceramic matrix, indicating a rhombohedral $R 3 c$ symmetry [50-52]. A minor orthorhombic Pbam impurity phase $\left(\mathrm{Bi}_{2} \mathrm{Fe}_{4} \mathrm{O}_{9}\right)$ was identified in the ceramic matrix as indicated by the circle in Fig. 2(g) with its SADP in Fig. 2(h). Fig. 3(a) and (b) show the TEM BFIs and SADPs in BFON10Nd. As evidenced in Fig. 3(a') and (a"), the SADPs confirm a dominant rhombohedral $R 3 c$ phase [50-52] with a minor orthorhombic Pbam phase $\left(\mathrm{Bi}_{2} \mathrm{Fe}_{4} \mathrm{O}_{9}\right)$ in the ceramic matrix as revealed by the Rietveld refinement [47]. These results are consistent with the previous XRD and TEM studies in $\left(\mathrm{Bi}_{1-x} \mathrm{Nd}_{x}\right) \mathrm{FeO}_{3}$ $(0 \leq x \leq 0.2)$ ceramics, which indicated a rhombohedral $R 3 c$ phase for $0 \leq x \leq 0.1[46,47]$. As shown in Fig. 3(b), a complicated microstructure with different contrast fringes suggests structural modulation defects resulting from composition fluctuations in the lattice, which can be attributed to inhomogeneous distributions of A-site ions. The SADPs along the [100]-zone axis in Fig. 3(b') and (b") reveal respectively a normal $R 3 c$ symmetry and a $R 3 c$ symmetry with coherent reflections resulting from a lattice fluctuation region. The TEM results confirm more structural defects in BFO10Nd than in BFO5Nd. This is consistent with the larger Urbach energy $\left(E_{U}\right)$ in BFO10Nd as shown in Fig. 1(b).

For photovoltaic measurements, a top electrode of n-type ITO thin film was deposited on ceramic surface as shown in Fig. 4(a), which demonstrates a cross section between the ITO thin film (thickness $100 \mathrm{~nm}$ ) and the BFO5Nd ceramic observed by brightfield TEM. The X-ray diffraction (XRD) pattern of the ITO thin film in Fig. 4(b) indicates a preferred (222) crystallographic orientation [53]. Fig. 4(c) is the photovoltaic experimental configuration for open-circuit voltage $\left(\mathrm{V}_{\mathrm{oc}}\right)$ and short-circuit current density $\left(\mathrm{J}_{\mathrm{sc}}\right)$ measurements. The $1 / 2(000)$ superlattice diffraction pattern along the [110]-zone axis in Fig. 4(d) confirms a $R 3 c$ phase in BFO5Nd [50,51].

Fig. 5(a) and (b) show open-circuit voltages $\left(\mathrm{V}_{\mathrm{oc}}\right)$ and shortcircuit current densities $\left(\mathrm{J}_{\mathrm{sc}}\right)$ measured from the heterostructures of ITO/BFO100 $x \mathrm{Nd}$ ceramics/Au as the laser irradiation $(\lambda=405 \mathrm{~nm})$ was switched on and off in sequence with increasing intensity $(I)$ by steps. Curves of $\mathrm{V}_{\mathrm{oc}}$ and $\mathrm{J}_{\mathrm{sc}} \mathrm{vs}$. irradiation intensity are plotted in Fig. 6(a) and (b), which show rapid increases for lower irradiation

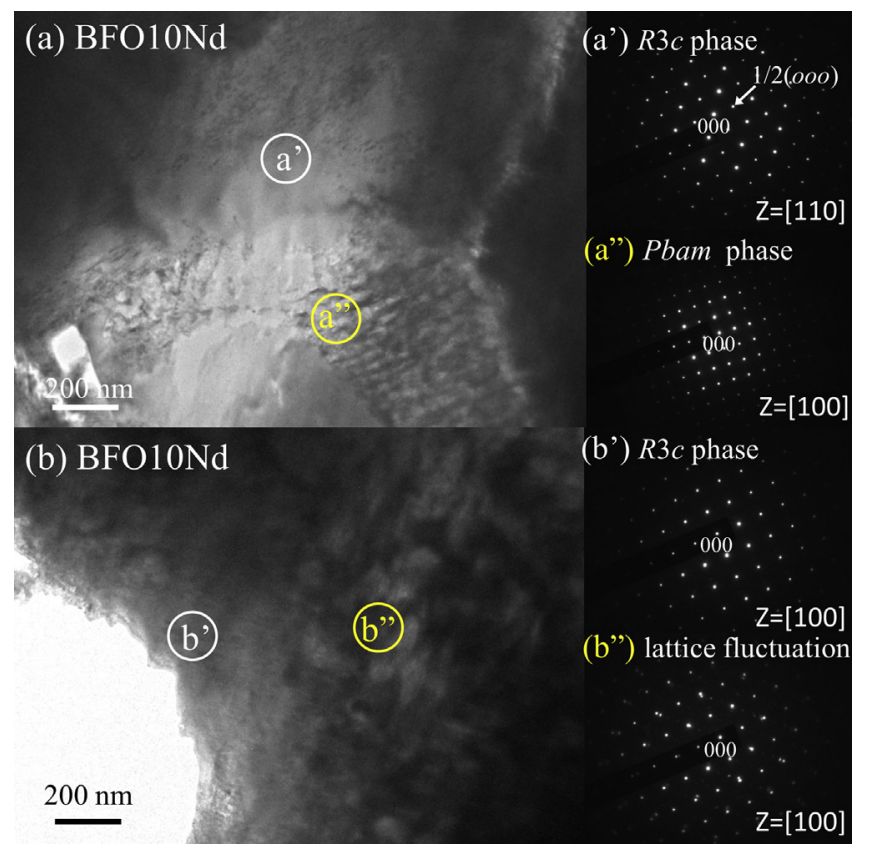

Fig. 3. TEM bright-field images and selected area diffraction patterns (SADPs) in BFO10Nd. 


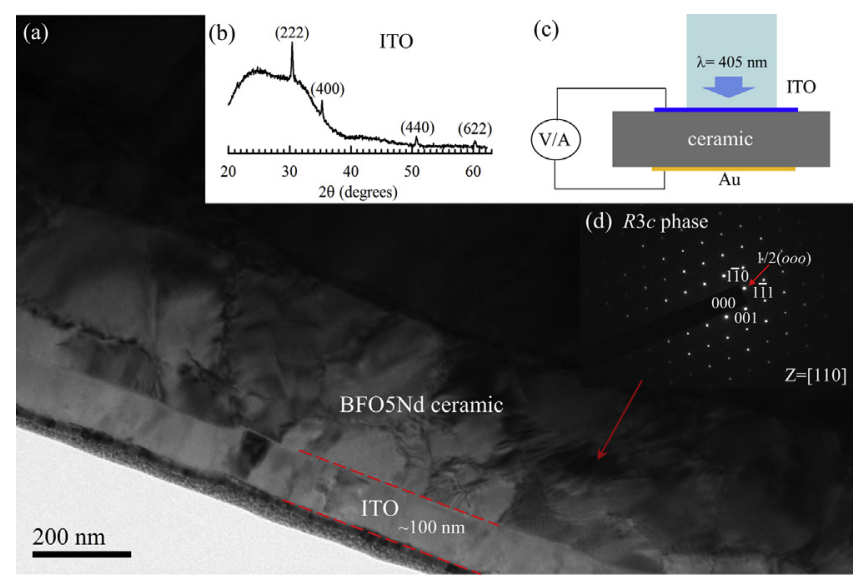

Fig. 4. (a) TEM bright-field image of cross section between the ITO thin film and BFO5Nd ceramic. (b) XRD pattern of ITO thin film (on the BK7 glass). (c) Photovoltaic experimental configuration for open-circuit voltage and short-circuit current. (d) SADP along the [110]-zone axis.

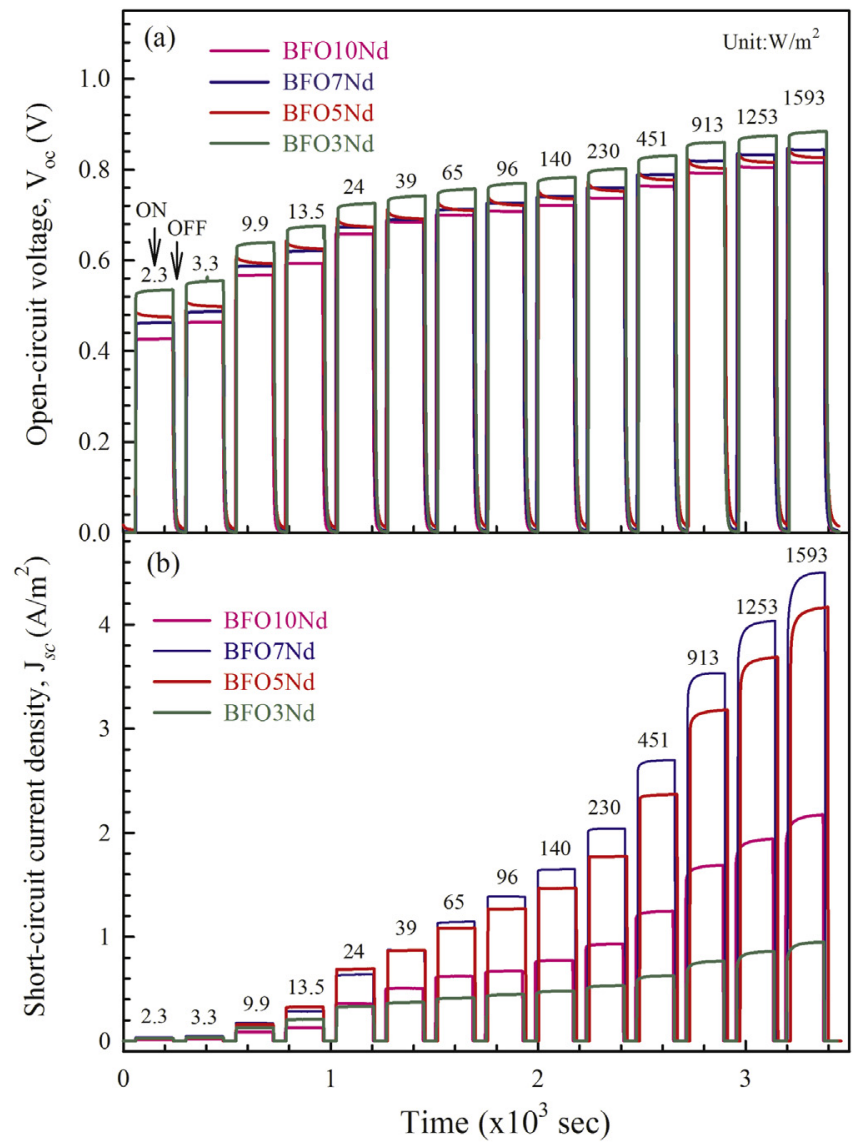

Fig. 5. (a) Open-circuit voltage $\left(\mathrm{V}_{\mathrm{oc}}\right)$ and (b) short-circuit current density $\left(\mathrm{J}_{\mathrm{sc}}\right)$ with increasing intensity. "ON" and "OFF" indicate with and without irradiation. The labeled numbers are irradiation intensities in $\mathrm{W} / \mathrm{m}^{2}$.

intensities $\left(<\sim 200 \mathrm{~W} / \mathrm{m}^{2}\right)$. Fig. 6(c) shows the external quantum efficiencies $\left(E Q E=h v J_{s c} / q I ; q=1.6 \times 10^{-19} \mathrm{C}\right)$, which is a conversion from incident photons to conduction electrons in the photovoltaic process [40]. BFO5Nd and BFO7Nd show respectively maximal EQEs of $\sim 9 \%$ and $\sim 8 \%$, which are remarkably larger than $\mathrm{EQE} \sim 1.11$ reported in $\mathrm{BaTiO}_{3}$ single crystal measured by the AFM tip under irradiation of $\lambda=405 \mathrm{~nm}[4]$.

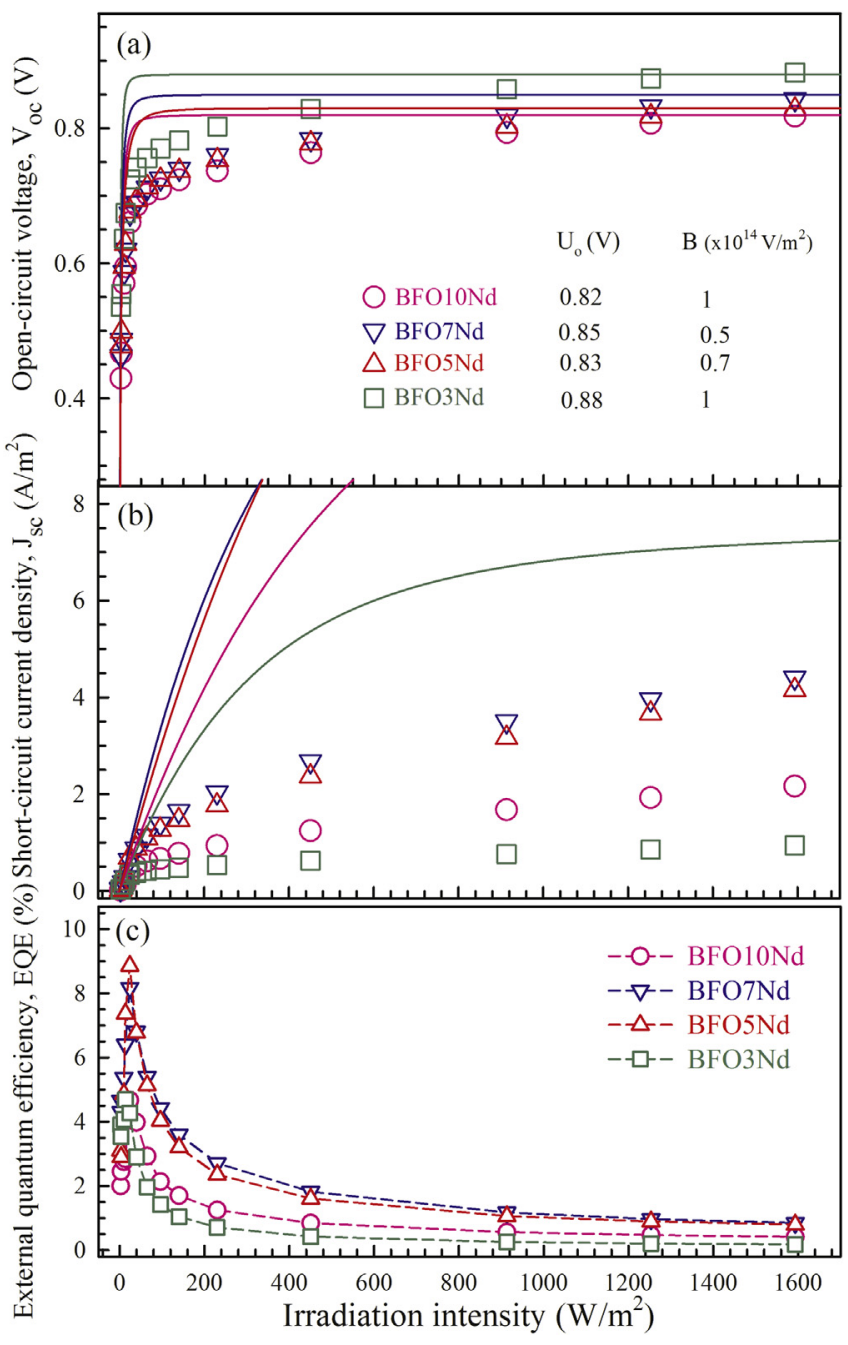

Fig. 6. Irradiation intensity-dependent (a) $\mathrm{V}_{\mathrm{O}}$, (b) $\mathrm{J}_{s c}$, and (c) EQE. The ceramic thickness is $0.15 \mathrm{~mm}$ for all samples. Solid lines in (a) and (b) are fits of Eqs. (6) and (7) with parameters in (a). Dashed lines in (c) are guides for the eye.

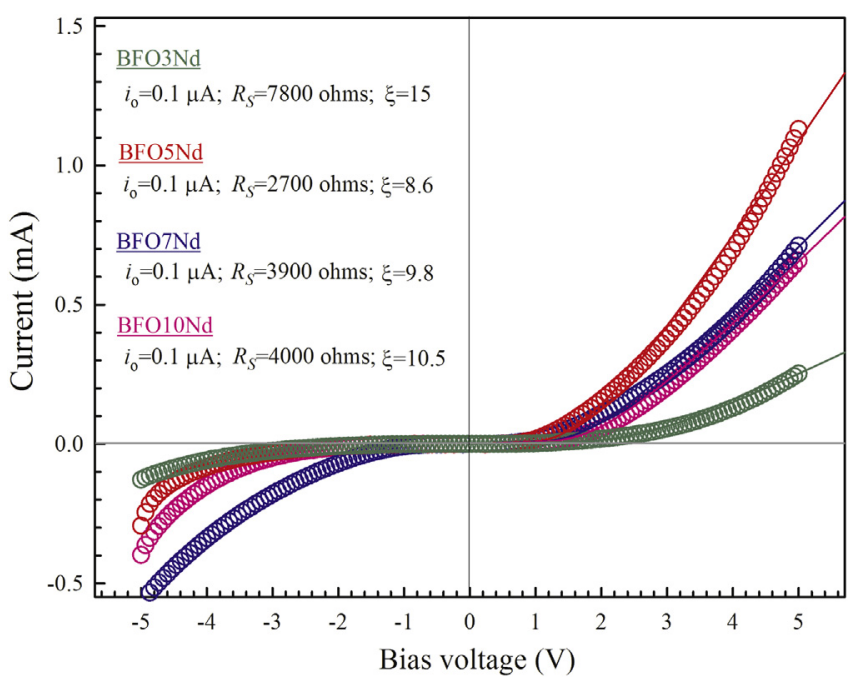

Fig. 7. Characteristic curves of current vs. bias voltage without irradiation. Solid lines are fits of Eq. (3) with parameters in the Figure. The ceramic thickness is $0.15 \mathrm{~mm}$. 


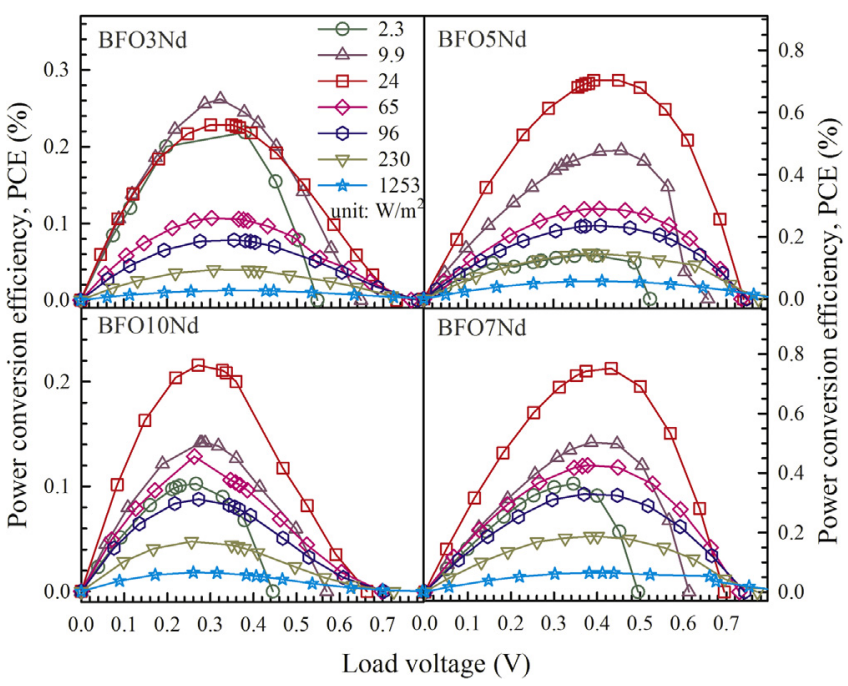

Fig. 8. Curves of power-conversion efficiency vs. load voltage $\left(V_{L}\right)$ for various irradiation intensities. The ceramic thickness is $0.15 \mathrm{~mm}$. Solid lines are guides for the eye.

To characterize the correlation between PV effects and irradiation intensity, we use a previously developed p-n-junction model to describe the irradiation intensity-dependent $\mathrm{V}_{\mathrm{oc}}$ and $\mathrm{J}_{\mathrm{sc}}[40,54]$. The photodiode current $i_{d}$ under a bias voltage $V$ without irradiation can be expressed by the implicit relation [55].

$i_{d}=i_{o}\left\{\exp \left[q\left(V-i_{d} R_{S}\right) / \xi k_{B} T\right]-1\right\}$

where $i_{0}, R_{s}$, and $\xi$ are respectively dark current, source resistance, and diode-quality factor. Fig. 7 shows characteristic curves of current vs. voltage without irradiation. The solid lines are fits of Eq. (3) with parameters as listed in the Figure. The electron charge $q=1.6 \times 10^{-19} \mathrm{C}$ and $\mathrm{T}=300 \mathrm{~K}$ were chosen for simplicity though irradiation may increase temperature at the junction. According to Eq. (3), the current i under irradiation can be written as [40].

$i_{d}=i_{o}\left\{\exp \left[q\left(V-i_{d} R_{S}\right) / \xi k_{B} T\right]-1\right\}$ where $i_{p}, i_{d}$, and $V$ are the photovoltaic (or photo-generated) current, diode current, and measured voltage.

For no irradiation, the open-circuit voltage $\mathrm{V}_{\mathrm{oc}}$ is cancelled by the built-in voltage $U_{0}$ from the ohmic contacts to the n-type ITO thin film and p-type BFO100xNd ceramics. In the depletion region, there exists a small density of thermally generated carriers (electrons and holes) with no net current. The photo-generated carriers will decrease the depletion region width and the retarding voltage, which limits the diffusion currents. The reduced depletion region width indicates a decrease in the downward voltage step $\left(U_{o c}\right)$ in the depletion region. Therefore, the open-circuit voltage $V_{\text {oc }}$ can be expressed as [40,54].

$V_{o c}(I)=U_{o}-U_{o c}(I)$

where $I$ is irradiation intensity. As derived in the previous work [40,54], the irradiation intensity-dependent open-circuit voltage $\left(\mathrm{V}_{\mathrm{oc}}\right)$ and short-circuit current $\left(\mathrm{i}_{\mathrm{sc}}\right)$ can be expressed by the following Equations [40];

$$
\begin{aligned}
V_{o c}= & U_{o}-B \beta^{2} i_{o}^{2}\left[\exp \left(V_{o c} q / \xi k T\right)-1\right]^{2} /(q S \lambda I / h c)^{2} \\
i_{S C}= & \left(U_{o} / R_{S}\right)-B \beta^{2}\left\{i_{s c}+i_{o}\left[\exp \left(i_{s c} R_{S} q / \xi k T\right)-1\right]\right\}^{2} / \\
& \times\left[R_{S}(q S \lambda I / h c)^{2}\right] \\
B= & \left(q n_{p} / 2 \varepsilon_{o} \varepsilon_{p}\right)+\left(1+n_{p} \varepsilon_{p} / \varepsilon_{n} n_{n}\right)
\end{aligned}
$$

where $S, \lambda, h$, and $c$ are irradiated area, irradiation wavelength, Planck constant, and light speed. $\beta$ is the optical attenuation length and can be determined from the transmission curve in Fig. 1(a), i.e. $\beta=-d / \ln (T)$. The optical attenuation lengths are respectively about $1.4,1.1,1.1$, and $1.2 \mu \mathrm{m}$ at $\lambda=405 \mathrm{~nm}$ for BFO3Nd, BFO5Nd, BFO7Nd, and BFO10Nd. $n_{p}$ and $n_{n}$ in Eq. (8) are the carrier densities of p-type BFO100xNd ceramics and n-type ITO thin film, respectively. $\varepsilon_{\mathrm{p}}$ and $\varepsilon_{\mathrm{n}}$ are the real parts of the dielectric permittivities. The roomtemperature dielectric permittivities $\left(\varepsilon_{\mathrm{p}}\right)$ are respectively 192,177 , 130 , and 180 for BFO3Nd, BFO5Nd, BFO7Nd, and BFO10Nd at measuring frequency $f=1 \mathrm{MHz}$. We used a Hall-effect measurement to determine carrier density of the n-type ITO thin film, which

\begin{tabular}{|c|c|c|c|c|c|c|}
\hline Heterostructures & $\mathrm{V}_{\mathrm{oc}}(\mathrm{V})$ & $\mathrm{J}_{\mathrm{sc}}\left(\mathrm{A} / \mathrm{m}^{2}\right)$ & $\begin{array}{l}\text { Maximal } \\
\text { PCE (\%) }\end{array}$ & EQE (\%) & $\begin{array}{l}\text { Irradiation } \lambda(\mathrm{nm}) / \text { intensity } \\
\left(\mathrm{W} / \mathrm{m}^{2}\right)\end{array}$ & References (mechanism) \\
\hline $\mathrm{BaTiO}_{3}$ crystal (AFM tip electrode) & & 363 & & 1.11 & $405 / 1000$ & [4] (BPVE) \\
\hline doped $\mathrm{LiNbO}_{3}$ crystal (transparent electrode) & $\sim 1600$ & $\sim 10^{-5}$ & & & $514.5 / 1500$ & [6] (BPVE) \\
\hline doped $\mathrm{BaTiO}_{3}$ ceramic (Au electrode) & $\sim 70$ & $\sim 10^{-6}$ & & & mercury arc lamp/100 & [7] (internal field) \\
\hline $\mathrm{Pt} / \mathrm{PZT}(52 / 48) / \mathrm{Ni}$ thin films & 0.8 & $6 \times 10^{-4}$ & & & $300-390 / 10$ & [12] (barrier PV effects) \\
\hline $\mathrm{Pt} / \mathrm{PZT}(20 / 80) / \mathrm{Pt}$ thin films & & 0.08 & & & $350-450 / 100$ & [13] (Schottky barrier) \\
\hline ITO/PZT(53/47)/ITO thin films & 0.25 & $5 \times 10^{-5}$ & 0.22 & & $632 / 4.5$ & [14] \\
\hline \multirow[t]{2}{*}{ LSMO/PLZT(3/52/48)/Nb:STO thin films } & $\sim 0.7$ & $\sim 0.02$ & $\sim 0.05$ & & $365 / \sim 8.5$ & [16] \\
\hline & $\sim 0.7$ & $\sim 0.01$ & $\sim 0.28$ & & $365 / \sim 0.59$ & \\
\hline $\mathrm{KNbO}_{3}-\mathrm{Ba}\left(\mathrm{Ni}_{1 / 2} \mathrm{Nb}_{1 / 2}\right) \mathrm{O}_{3}$ ceramic (ITO electrode) & $\sim 7 \times 10^{-4}$ & $\sim 10^{-3}$ & & & halogen lamp/40 & [18] (ferroelectric-metal interface) \\
\hline ITO/doped PMN-PT crystal/ITO & $<0.2$ & & & & $406 / 2600$ & [19] \\
\hline $\mathrm{Au} / \mathrm{BFO}$ crystal/Au & & 0.075 & & & 532 & [23] (diode effect) \\
\hline ITO/BFO/SRO thin films & 0.3 & $4 \times 10^{-3}$ & & & $435 / 7.5$ & [24] (BPVE) \\
\hline Pt/BFO crystal/Pt (AFM tip electrode) & 13 & 0.01 & & $3 \times 10^{-5}$ & 405 & [35] \\
\hline ITO/BFO ceramic/Au & 0.58 & 0.05 & 0.005 & 0.16 & $405 / 100$ & [42] (p-n junction) \\
\hline ITO/BFO5Sm ceramic/Au & 0.7 & 0.94 & 0.25 & 3 & $405 / 100$ & [42] (p-n junction) \\
\hline Pt/BFO/Pt thin films & 20 & 0.5 & & & $375 / 1000$ & [60] (domain walls) \\
\hline ITO $/ \mathrm{Bi}_{2} \mathrm{FeCrO}_{6} / \mathrm{Nb}: \mathrm{STO}$ thin films & $\sim 0.6$ & $\sim 1.1 / 9.9$ & & $\sim 0.8 / 6$ & $635 / 15$ & [61] \\
\hline ITO/BFO3Nd ceramic/Au $(\mathrm{d}=0.15 \mathrm{~mm})$ & 0.77 & 0.45 & 0.08 & 1.4 & $405 / \sim 100$ & This work ( $\mathrm{p}-\mathrm{n}$ junction) \\
\hline ITO/BFO5Nd ceramic/Au $(\mathrm{d}=0.15 \mathrm{~mm})$ & 0.72 & 1.27 & 0.24 & 4.0 & $405 / \sim 100$ & This work ( $p-n$ junction) \\
\hline ITO/BFO7Nd ceramic/Au $(\mathrm{d}=0.15 \mathrm{~mm})$ & 0.73 & 1.39 & 0.32 & 4.4 & $405 / \sim 100$ & This work ( $\mathrm{p}-\mathrm{n}$ junction) \\
\hline ITO/BFO10Nd ceramic/Au $(\mathrm{d}=0.15 \mathrm{~mm})$ & 0.71 & 0.67 & 0.09 & 2.1 & $405 / \sim 100$ & This work ( $\mathrm{p}-\mathrm{n}$ junction) \\
\hline
\end{tabular}

Table 1

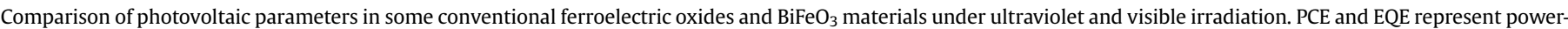

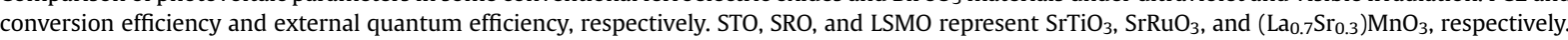


is $\mathrm{n}_{\mathrm{n}} \sim 6 \times 10^{26} \mathrm{~m}^{-3}$ and is consistent with the reported value of $\sim 10^{27} \mathrm{~m}^{-3}$ [56]. The permittivity $\in_{n}$ of ITO at low frequency as needed in Eq. (8) has not been measured because of the high conductivity of bulk ITO. However, Eq. (8) applies to the depletion region of ITO which is almost free of charge carriers. Accordingly, the relevant permittivity is expected to be near that of a material with structure close to that of ITO (indium tin oxide) but without the high conductivity of ITO. Indium oxide $\left(\mathrm{In}_{2} \mathrm{O}_{3}\right)$ thin film at $300 \mathrm{~K}$ and $1 \mathrm{kHz}$ has $\in^{\prime} \sim 37$ [57]. If the depletion region of ITO has $\in_{n}$ near this value, the $\in_{p} \mathrm{n}_{p} / \in_{n} \mathrm{n}_{n}$ term in Eq. (8) is much smaller than 1 and so is negligible. Thus, from Eq. (8) the carrier densities $n_{p}$ can be calculated by the approximate relation, $\mathrm{n}_{\mathrm{p}} \sim 2 B \varepsilon_{\mathrm{o}} \varepsilon_{\mathrm{p}} / q$. The estimated carrier densities $\mathrm{n}_{\mathrm{p}}$ are about $2 \times 10^{24}, 1 \times 10^{24}, 7 \times 10^{23}$, and $2 \times 10^{24} \mathrm{~m}^{-3}$ for BFO3Nd, BFO5Nd, BFO7Nd, and BFO10Nd, respectively. These carrier densities are comparable with $\mathrm{n}_{\mathrm{p}} \sim 10^{23} \mathrm{~m}^{-3}$ reported for epitaxial BFO thin film [39]. The slightly larger carrier densities in BFO3Nd and BFO10Nd may be associated with local structural defects as revealed by TEM (Fig. 3) and Urbach energy (Fig. 1), which may indicate increased charge carrier concentrations. The $\mathrm{p}-\mathrm{n}$ junction width $\mathrm{d}_{\mathrm{o}}$ (without irradiation) between the ceramic layer and the ITO thin film can be estimated by using the relation, $d_{0} \sim\left(U_{o} / B\right)^{1 / 2}$ [40]. The calculated p-n-junction widths $d_{o}$ are respectively about $94,109,130$, and $91 \mathrm{~nm}$ for BFO3Nd, BFO5Nd, BFO7Nd, and BFO10Nd and are fairly consistent with the depletion layer width between the ITO and BFO thin films, which was estimated to be a few hundred nanometers [39].

The solid lines in Fig. 6(a) and (b) are theoretical fits of $\mathrm{V}_{\mathrm{oc}}$ and $\mathrm{J}_{\mathrm{sc}}$ $\left(=i_{\mathrm{sc}} / S\right)$ by using Eqs. (6) and (7) respectively with parameters in Fig. 6(a). The calculated curves agree well quantitatively with experimental data at the lower irradiation intensities. The discrepancies between the experimental and calculated $V_{\text {oc }}$ at higher irradiation intensities mainly result from increase of the intrinsic carrier density. As irradiation intensity increases, the fermi level can be pushed higher due to increasing thermal energy. The built-in potential barrier $\left(U_{0}\right)$ in a $p-n$ junction is mainly caused by the difference in fermi levels between the p-type and n-type regions. Thus, the built-in voltage $\left(U_{0}\right)$ is expected to decrease as the band gap of the fermi levels decreases with increasing irradiation intensity.

The experimental $\mathrm{J}_{\mathrm{sc}}$ exhibits a rapid deviation from the theoretical curves with increasing irradiation intensity as shown in Fig. 6(b). The reduction of photo-generated current can be
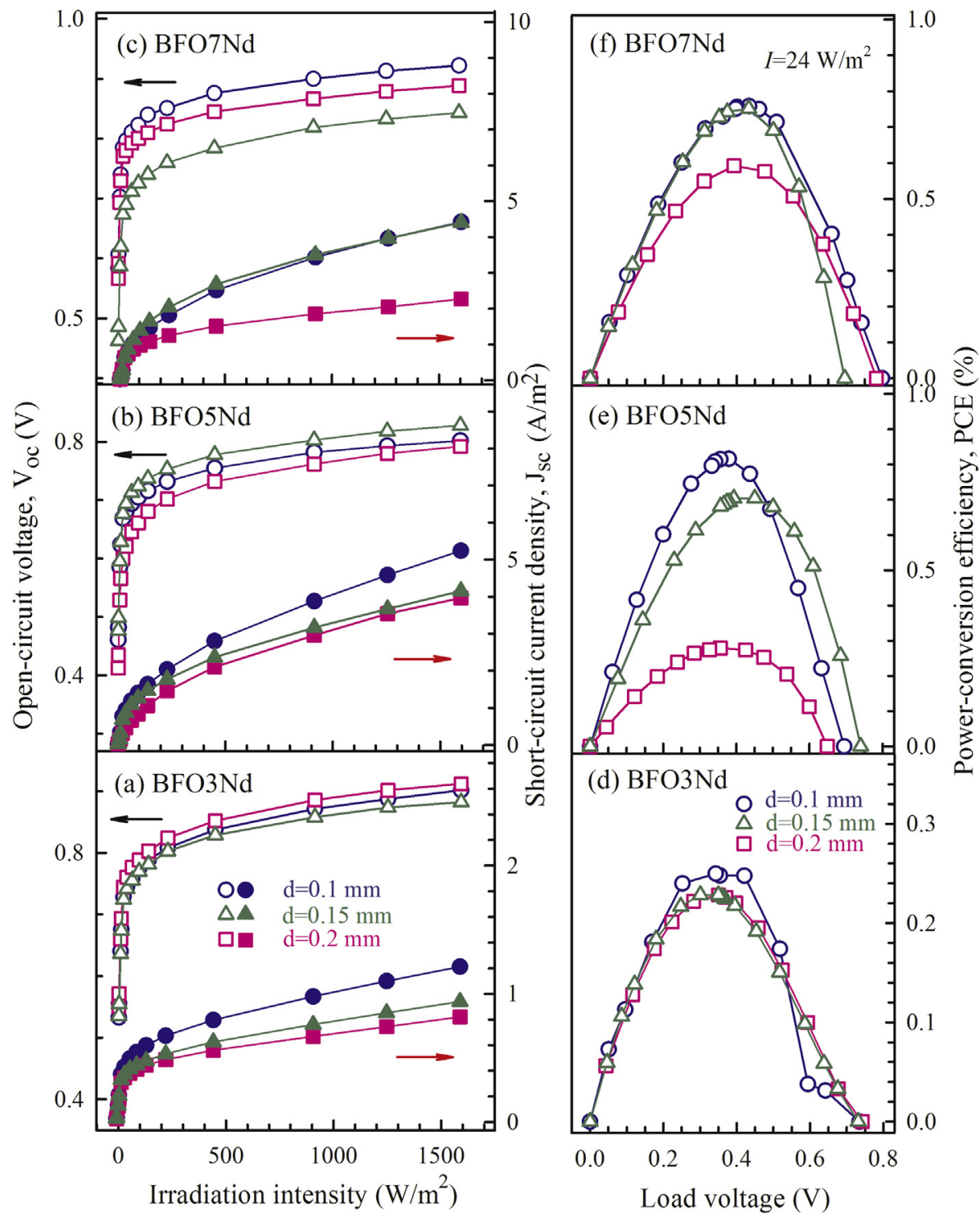

Fig. 9. $(a-c) V_{o c}$ and $J_{s c}$ vs. irradiation intensity for various ceramic thicknesses (d). (d-f) Plots of PCE vs. $V_{L}$ at $I=24 \mathrm{~W} / \mathrm{m}^{2}$. Solid lines are guides for the eye. 
Table 2

Comparison of photovoltaic parameters $\left(\mathrm{V}_{\mathrm{oc}}, \mathrm{J}_{\mathrm{sc}}, \mathrm{EQE}\right.$, and maximal PCE) for different ceramic thicknesses.

\begin{tabular}{|c|c|c|c|c|}
\hline Heterostructures & $\mathrm{V}_{\mathrm{oc}}(\mathrm{V})$ at $\mathrm{I} \sim 910 \mathrm{~W} / \mathrm{m}^{2}$ & $\mathrm{~J}_{\mathrm{sc}}\left(\mathrm{A} / \mathrm{m}^{2}\right)$ at $\mathrm{I} \sim 910 \mathrm{~W} / \mathrm{m}^{2}$ & $\mathrm{EQE}(\%)$ at $\mathrm{I} \sim 910 \mathrm{~W} / \mathrm{m}^{2}$ & Maximal PCE (\%) at I $24 \mathrm{~W} / \mathrm{m}^{2}$ \\
\hline \multicolumn{5}{|l|}{ ITO/BFO3Nd/Au } \\
\hline $\mathrm{d}=0.10 \mathrm{~mm}$ & 0.87 & 0.98 & 0.33 & 0.25 \\
\hline $0.15 \mathrm{~mm}$ & 0.86 & 0.76 & 0.26 & 0.23 \\
\hline $0.20 \mathrm{~mm}$ & 0.89 & 0.67 & 0.23 & 0.23 \\
\hline \multicolumn{5}{|l|}{ ITO/BFO5Nd/Au } \\
\hline $\mathrm{d}=0.10 \mathrm{~mm}$ & 0.78 & 3.88 & 1.31 & 0.82 \\
\hline $0.15 \mathrm{~mm}$ & 0.80 & 3.17 & 1.07 & 0.70 \\
\hline $0.20 \mathrm{~mm}$ & 0.76 & 2.96 & 1.00 & 0.28 \\
\hline \multicolumn{5}{|l|}{ ITO/BFO7Nd/Au } \\
\hline $\mathrm{d}=0.10 \mathrm{~mm}$ & 0.90 & 3.44 & 1.16 & 0.76 \\
\hline $0.15 \mathrm{~mm}$ & 0.82 & 3.50 & 1.18 & 0.75 \\
\hline $0.20 \mathrm{~mm}$ & 0.87 & 1.86 & 0.63 & 0.59 \\
\hline
\end{tabular}

attributed mainly to the carrier recombination, which can occur both at the surface and in the bulk of the cell. The carrier recombination is also responsible for the rapid decay in the EQE with increasing irradiation intensity as shown in Fig. 6(c). The p-njunction model used in this study only considers the electron-hole generation by irradiation [40]. The smaller $\mathrm{J}_{\mathrm{sc}}$ in BFO3Nd and BFO10Nd may be associated with oxygen vacancies, because oxygen vacancies can increase charge recombination rate at the interface [58]. It was reported that local domain structure, polarization, and electronic states may also affect the PV responses [25,59].

Fig. 8 shows plots of power-conversion efficiency (PCE) vs. load voltage $\left(V_{L}\right)$ for various irradiation intensities. The maximal powerconversion efficiencies (PCEs) occur at lower intensities and are respectively about $0.26,0.70,0.75$, and $0.22 \%$ for $\mathrm{BFO} 3 \mathrm{Nd}$, BFO5Nd, $\mathrm{BFO7Nd}$, and BFO10Nd. The decrease of PCEs for higher irradiation intensities can be mainly due to the recombination of charge carriers as discussed above. A brief summary of experimental PV parameters under ultraviolet-visible irradiations is given in Table 1, including previous PV results in some conventional perovskite ferroelectric/piezoelectric oxides and BFO materials with various electrodes [4,6,7,12-14,16,18,19,23,24,35,42,60,61]. The maximal photovoltaic PCEs obtained in this work are comparable or larger than those in most conventional ferroelectric oxides and $\mathrm{BiFeO}_{3}$ materials under ultraviolet or visible irradiation.

Fig. $9(\mathrm{a}-\mathrm{c})$ show curves of $\mathrm{V}_{\mathrm{oc}}$ and $\mathrm{J}_{\mathrm{sc}}$ for three different ceramic thicknesses (d) of 0.1, 0.15, and $0.2 \mathrm{~mm}$ for BFO3Nd, BFO5Nd, and BFO7Nd. A brief list of PV parameters $\left(\mathrm{V}_{\mathrm{oc}}, \mathrm{J}_{\mathrm{sc}}, \mathrm{EQE}\right.$, and maximal PCE) for different ceramic thicknesses is given in Table 2 at irradiation intensities of 24 and $910 \mathrm{~W} / \mathrm{m}^{2}$. Thickness-dependent plots of power-conversion efficiency $(\mathrm{PCE})$ vs. load voltage $\left(\mathrm{V}_{\mathrm{L}}\right)$ at irradiation intensity $I=24 \mathrm{~W} / \mathrm{m}^{2}$ are given in Fig. $9(\mathrm{~d}-\mathrm{f})$. The maximal PCEs at $\mathrm{d}=0.1 \mathrm{~mm}$ for BFO3Nd, BFO5Nd, and BFO7Nd can respectively reach $\sim 0.25, \sim 0.82$, and $\sim 0.76 \%$, which are respectively larger than $\sim 0.23, \sim 0.28$, and $\sim 0.59 \%$ at $\mathrm{d}=0.2 \mathrm{~mm}$. As shown in Table 2 , $\mathrm{J}_{\mathrm{sc}}, \mathrm{EQE}$, and PCE decrease with increasing ceramic thickness, but $\mathrm{V}_{\mathrm{oc}}$ does not show consistent thickness dependence. Thicknessdependent PV effects were also reported in ITO/BFO/SRO [39] and $\mathrm{Au} / \mathrm{BFO} / \mathrm{Pt}$ [62] thin film heterostructures, in which $\mathrm{V}_{\mathrm{oc}}$ shows a rapid decrease with decreasing thin film thickness below a few hundreds of nanometers and was correlated to ferroelectric polarization at the junction layer. However, $\mathrm{BiFeO}_{3}$ ceramics do not exhibit macroscale saturated ferroelectric polarization hysteresis loop mainly due to current leakage $[63,64]$. In our previous study for $\left(\mathrm{Bi}_{1-x} \mathrm{Nd}_{x}\right) \mathrm{FeO}_{3}(0 \leq x \leq 0.10)$ ceramics [47], the local domain switching as found from piezoresponse force microscopy revealed coexistence of polar ferroelectric rhombohedral and minor nonpolar orthorhombic phases in the ceramic matrix. The decreased $\mathrm{J}_{\mathrm{sc}}, \mathrm{EQE}$, and PCE with increasing ceramic thickness in
Fig. 9 and Table 2 can be mainly attributed to recombination of photo-generated carriers while they travel through ceramic matrix from the $p-n$ junction to the bottom electrode. Local domain walls [37], nano-to-micro domain structures [42], and atomic orbital hybridizations [42] are also suggested to contribute to the PV responses. The stronger PCEs and EQEs in BFO5Nd and BFO7Nd are likely associated with less structural defects as revealed by highresolution TEM observations in Figs. 2 and 3.

\section{Conclusions}

This study demonstrated extraordinary junction-driven photovoltaic effects in the heterostructure consisting of lead-free ( $\mathrm{Bi}_{1}$ $\left.{ }_{x} \mathrm{Nd}_{x}\right) \mathrm{FeO}_{3}$ multiferroic ceramics and ITO thin film (top electrode) under irradiation $(\lambda=405 \mathrm{~nm})$. The maximal power-conversion efficiency (PCE) and external quantum efficiency (EQE) can respectively reach $\sim 0.8 \%$ and $\sim 9 \%$ at lower irradiation intensity. The photovoltaic effects show strong dependences on irradiation intensity, ceramic thickness, and Nd concentration. The photogenerated open-circuit voltage $\left(\mathrm{V}_{\mathrm{oc}}\right)$ and short-circuit current density $\left(\mathrm{Js}_{\mathrm{c}}\right.$ ) can be quantitatively described by a p-n-junction model as functions of irradiation intensity. Microstructure defects are likely responsible for the decrease of direct optical band gaps from $2.19 \mathrm{eV}$ in BFO3Nd to $2.12 \mathrm{eV}$ in BFO10Nd.

\section{Acknowledgement}

This project is supported by the Ministry of Science and Technology of Taiwan under Project Nos. MOST105-2221-E-030-002MY3, MOST106-2221-E-131-005, and MOST106-2221-E-146-003.

\section{References}

[1] J. Kreisel, M. Alexe, P.A. Thomas, A photoferroelectric material is more than the sum of its parts, Nat. Mater. 11 (2012) 260.

[2] S.M. Young, F. Zheng, A.M. Rappe, First principles calculation of the bulk photovoltaic effect in bismuth ferrite, Phys. Rev. Lett. 109 (2012) 236601 (5pp).

[3] V.M. Fridkin, Parity nonconservation and bulk photovoltaic effect in the crystal without symmetry center, IEEE Trans. Ultrason. Ferroelectrics Freq. Contr. 60 (2013) 1551-1555.

[4] J.E. Spanier, V.M. Fridkin, A.M. Rappe, A.R. Akbashev, A. Polemi, Y. Qi, Z. Gu, S.M. Young, C.J. Hawley, D. Imbrenda, G. Xiao, A.L. Bennett-Jackson, C.L. Johnson, Power conversion efficiency exceeding the Shockley-Queisser limit in a ferroelectric insulator, Nat. Photon. 10 (2016) 611-616.

[5] A.A. Grekov, M.A. Malitskaya, V.D. Spitsina, V.M. Fridkin, Photoelectric effects in $A^{5} B^{6} C^{7}$-type ferroelectrics-semiconductors with low-temperature phase transitions, Kristallografiya 15 (1970) 500-509 [Sov. Phys. Crystallogr. 15(1970) 423-430]

[6] A.M. Glass, L.D. von der Linde, T.J. Negran, High-voltage bulk photovoltaic effect and the photorefractive process in $\mathrm{LiNbO}_{3}$, Appl. Phys. Lett. 25 (1974) 233-235.

[7] P.S. Brody, Large polarization-dependent photovoltages in ceramic $\mathrm{BaTiO}_{3}+5 \mathrm{wt} \% \mathrm{CaTiO}_{3}$, Solid State Commun. 12 (1973) 12, 673-676. 
[8] A. Kholkin, O. Boiarkine, N. Setter, Transient photocurrents in lead zirconate titanate thin films, Appl. Phys. Lett. 72 (1998) 130-132.

[9] A.L. Kholkin, V.K. Yarmarkin, B.M. Goltsman, J.L. Baptista, Photoelectric evaluation of polarization and internal field in PZT thin films, Integrated Ferroelectrics 35 (2001) 261-268.

[10] A. Kholkin, O. Bolarkine, N. Setter, Transient photocurrents in lead zirconate titanate thin films, Appl. Phys. Lett. 72 (1998) 130-132.

[11] Y.S. Yang, S.J. Lee, S. Yi, B.G. Chae, S.H. Lee, H.J. Joo, M.S. Jang, Schottky barrier effects in the photocurrent of sol-gel derived lead zirconate titanate thin film capacitors, Appl. Phys. Lett. 76 (2000) 774-776.

[12] V. Yarmarkin, B. Gol'tsman, M. Kazanin, V. Lemanov, Barrier photovoltaic effects in PZT ferroelectric thin films, Phys. Solid State 42 (2000) 522-527.

[13] F. Zheng, J. Xu, L. Fang, M. Shen, X. Wu, Separation of the Schottky barrier and polarization effects on the photocurrent of Pt sandwiched $\mathrm{Pb}\left(\mathrm{Zr}_{0.20} \mathrm{Ti}_{0.80}\right) \mathrm{O}_{3}$ films, Appl. Phys. Lett. 93 (2008) 172101 (3pp).

[14] B. Chen, Z. Zuo, Y. Liu, Q.-F. Zhan, Y. Xie, H. Yang, G. Dai, Z. Li, G. Xu, R.-W. Li, Tunable photovoltaic effects in transparent $\mathrm{Pb}\left(\mathrm{Zr}_{0.53} \mathrm{Ti}_{0.47}\right) \mathrm{O}_{3}$ capacitors, Appl. Phys. Lett. 100 (2012) 173903 (4pp).

[15] K. Uchino, P. Poosanaas, K. Tonooka, Photostrictive actuators, Ferroelectrics 264 (2001) 303-308

[16] M. Qin, K. Yao, Y.C. Liang, High efficient photovoltaics in nanoscaled ferroelectric thin films, Appl. Phys. Lett. 93 (2008) 122904 (3pp).

[17] M. Qin, K. Yao, Y.C. Liang, S. Shannigrahi, Thickness effects on photoinduced current in ferroelectric $\left(\mathrm{Pb}_{0.97} \mathrm{La}_{0.03}\right)\left(\mathrm{Zr}_{0.52} \mathrm{Ti}_{0.48}\right) \mathrm{O}_{3}\left(\mathrm{~Pb}_{0.97} \mathrm{La}_{0.03}\right)\left(\mathrm{Zr}_{0.52} \mathrm{Ti}_{0.48}\right) \mathrm{O}_{3}$ thin films, J. Appl. Phys. 101 (2007) 014104 (8pp).

[18] I. Grinberg, D.V. West, M. Torres, G. Gou, D.M. Stein, L. Wu, G. Chen, E.M. Gallo, A.R. Akbashev, P.K. Davies, J.E. Spanier, A.M. Rappe, Perovskite oxides for visible-light-absorbing ferroelectric and photovoltaic materials, Nature 503 (2013) 509-512.

[19] C.S. Tu, F.T. Wang, R.R. Chien, V.H. Schmidt, C.M. Hung, C.T. Tseng, Dielectric and photo-voltaic phenomena in tungsten doped $\mathrm{Pb}\left(\mathrm{Mg}_{1 / 3} \mathrm{Nb}_{2 / 3}\right)_{1-x} \mathrm{Ti}_{x} \mathrm{O}_{3}$ crystal, Appl. Phys. Lett. 88 (2006) 032902 (3pp).

[20] B.I. Sturman, V.M. Fridkin, The Photovoltaic and Photorefractive Effects in Noncentrosymmetric Materials, Gordon and Breach, 1992.

[21] D. Cao, C. Wang, F. Zheng, W. Dong, L. Fang, M. Shen, High-efficiency ferroelectric-film solar cells with an n-type $\mathrm{Cu}_{2} \mathrm{O}$ cathode buffer layer, Nano Lett. 12 (2012) 2803-2809.

[22] F. Wang, L. Grinberg, A.M. Rappe, Band gap engineering strategy via polarization rotation in perovskite ferroelectrics, Appl. Phys. Lett. 104 (2014) 152903 (4pp).

[23] T. Choi, S. Lee, YJ. Choi, V. Kiryukhin, S.-W. Cheong, Switchable ferroelectric diode and photovoltaic effect in $\mathrm{BiFeO}_{3}$, Science 324 (2009) 63-66.

[24] W. Ji, K. Yao, Y.C. Liang, Bulk photovoltaic effect at visible wavelength in epitaxial ferroelectric $\mathrm{BiFeO}_{3}$ thin films, Adv. Mater. 22 (2010) 1763-1766.

[25] N.A. Spaldin, S.W. Cheong, R. Ramesh, Multiferroics: past, present, and future, Phys. Today 63 (2010) 38-43.

[26] C. Himcinschi, I. Vrejoiu, M. Friedrich, E. Nikulina, L. Ding, C. Cobet, N. Esser M. Alexe, D. Rafaja, D.R.T. Zahn, Substrate influence on the optical and structural properties of pulsed laser deposited $\mathrm{BiFeO}_{3}$ epitaxial films, J. Appl. Phys. 107 (2010) 123524 (5pp).

[27] Y. Zang, D. Xie, X. Wu, Y. Chen, Y. Lin, M. Li, H. Tian, X. Li, Z. Li, H. Zhu, T. Ren, D. Plant, Enhanced photovoltaic properties in graphene/polycrystalline $\mathrm{BiFeO}_{3} / \mathrm{Pt}$ heterojunction structure, Appl. Phys. Lett. 99 (2011) 132904 (3pp).

[28] B. Chen, M. Li, Y. Liu, Z. Zuo, F. Zhuge, Q.F. Zhan, R.W. Li, Effect of top elec trodes on photovoltaic properties of polycrystalline $\mathrm{BiFeO}_{3}$ based thin film capacitors, Nanotechnology 22 (2011) 195201 (5pp).

[29] W. Ji, K. Yao, Y.C. Liang, Evidence of bulk photovoltaic effect and large tensor coefficient in ferroelectric $\mathrm{BiFeO}_{3}$ thin films, Phys. Rev. B 84 (2011) 094115 (5pp).

[30] S.Y. Yang, J. Seidel, S.J. Byrnes, P. Shafer, C.-H. Yang, M.D. Rossell, P. Yu, Y.H. Chu, J.F. Scott, J.W. Ager III, L.W. Martin, R. Ramesh, Above-bandgap voltages from ferroelectric photovoltaic devices, Nat. Nanotechnol. 5 (2010) $143-147$.

[31] H.T. Yi, T. Choi, S.G. Choi, Y.S. Oh, S.-W. Cheong, Mechanism of the switchable photovoltaic effect in ferroelectric $\mathrm{BiFeO}_{3}$, Adv. Mater. 23 (2011) 3403-3407.

[32] Y.B. Chen, M.B. Katz, X.Q. Pan, R.R. Das, D.M. Kim, S.H. Baek, C.B. Eom Ferroelectric domain structures of epitaxial (001) $\mathrm{BiFeO}_{3}$ thin films, Appl Phys. Lett. 90 (2007) 072907 (3pp).

[33] B. Kundys, M. Viret, D. Colson, D.O. Kundys, Light-induced size changes in $\mathrm{BiFeO}_{3}$ crystals, Nat. Mater. 9 (2010) 803-805.

[34] J.F. Ihlefeld, N.J. Podraza, Z.K. Liu, R.C. Rai, X. Xu, T. Heeg, Y.B. Chen, J. Li, R.W. Collins, J.L. Musfeldt, X.Q. Pan, J. Schubert, R. Ramesh, D.G. Schlom, Optical band gap of $\mathrm{BiFeO}_{3}$ grown by molecular-beam epitaxy, Appl. Phys. Lett. 92 (2008) 142908 (3pp).

[35] M. Alexe, D. Hesse, Tip-enhanced photovoltaic effects in bismuth ferrite, Nat. Commun. 2 (2011) 256 (5pp)

[36] G.G. Khan, R. Das, N. Mukherjee, K. Mandal, Effect of metal doping on highly efficient photovoltaics and switchable photovoltage in bismuth ferrite nanotubes, Phys. Status Solidi RRL 6 (2012) 312-314.

[37] A. Bhatnagar, A.R. Chaudhuri, Y.H. Kim, D. Hesse, M. Alexe, Role of domain walls in the abnormal photovoltaic effect in $\mathrm{BiFeO}_{3}$, Nat. Commun. 4 (2013) 2835 (8pp).

[38] J. Chakrabartty, R. Nechache, S. Li, M. Nicklaus, A. Ruediger, F. Rosei,
Photovoltaic properties of multiferroic $\mathrm{BiFeO}_{3} / \mathrm{BiCrO}_{3}$ heterostructures, J. Am. Ceram. Soc. 97 (2014) 1837-1840.

[39] S.Y. Yang, L.W. Martin, S.J. Bymes, T.E. Conry, S.R. Basu, D. Paran, L. Reichertz, J. Ihlefeld, C. Adamo, A. Melville, Y.-H. Chu, C.-H. Yang, J.L. Musfeldt, D.G. Schlom, J.W. Ager, R. Ramesh, Photovoltaic effects in $\mathrm{BiFeO}_{3}$, Appl. Phys. Lett. 95 (2009) 062909 (3pp).

[40] C.S. Tu, C.M. Hung, Z.R. Xu, V.H. Schmidt, Y. Ting, R.R. Chien, Y.T. Peng, J. Anthoninappen, Calcium-doping effects on photovoltaic response and structure in multiferroic $\mathrm{BiFeO}_{3}$ ceramics, J. Appl. Phys. 114 (2013) 124105 (6pp).

[41] Y.T. Peng, S.H. Chiou, C.H. Hsiao, C. Ouyang, C.S. Tu, Remarkably enhanced photovoltaic effects and first-principles calculations in neodymium doped $\mathrm{BiFeO}_{3}$, Sci. Rep. 7 (2017) 45164 (9pp).

[42] C.S. Tu, C.S. Chen, P.Y. Chen, H.H. Wei, V.H. Schmidt, C.Y. Lin, J. Anthoniappen, J.-M. Lee, Enhanced photovoltaic effects in A-site samarium doped $\mathrm{BiFeO}_{3}$ ceramics: the roles of domain structure and electronic state, J. Eur. Ceram. Soc. 36 (2016) 1149-1157.

[43] C.S. Tu, P.Y. Chen, C.S. Chen, C.Y. Lin, V.H. Schmidt, Tailoring microstructure and photovoltaic effect in multiferroic Nd-substituted $\mathrm{BiFeO}_{3}$ ceramics by processing atmosphere modification, J. Eur. Ceram. Soc. 38 (2018) 1389-1398.

[44] R. Agarwal, Y. Sharma, R.S. Katiyar, Switchable photovoltaic and polarization modulated rectification in Si-integrated $\mathrm{Pt} /\left(\mathrm{Bi}_{0.9} \mathrm{Sm}_{0.1}\right)\left(\mathrm{Fe}_{0.97} \mathrm{Hf}_{0.03}\right) \mathrm{O}_{3} / \mathrm{LaNiO}_{3}$ heterostructures, Appl. Phys. Lett. 107 (2015) 162904 (5pp).

[45] D. Kan, L. Pálová, V. Anbusathaiah, C.J. Cheng, S. Fujino, V. Nagarajan, K.M. Rabe, I. Takeuchi, Universal behavior and electric-field-induced structural transition in rare-earth-substituted $\mathrm{BiFeO}_{3}$, Adv. Funct. Mater. 20 (2010) $1108-1115$.

[46] S. Karimi, I.M. Reaney, I. Levin, I. Sterianou, Nd-doped ceramics with antipolar order, Appl. Phys. Lett. 94 (2009) 112903 (3pp).

[47] W.S. Chang, C.S. Tu, P.Y. Chen, C.S. Chen, C.Y. Lin, K.C. Feng, Y.L. Hsieh, Y.H. Huang, Effects of Fe $3 \mathrm{~d}-\mathrm{O} 2 \mathrm{p}$ and $\mathrm{Bi} 6 \mathrm{sp}-\mathrm{O} 2 \mathrm{p}$ orbital hybridizations in Nd doped $\mathrm{BiFeO}_{3}$ ceramics, J. Alloy. Comp. 710 (2017) 670-679.

[48] R. Bhatt, I. Bhaumik, S. Ganesamoorthy, A.K. Karnal, M.K. Swami, H.S. Patel, P.K. Gupta, Urbach tail and bandgap analysis in near stoichiometric $\mathrm{LiNbO}_{3}$ crystals, Phys. Status Solidi 209 (2012) 176-180.

[49] K.K. Nanda, F.E. Krius, H. Fissan, M. Acet, Band-gap tuning of PbS nanoparticles by in-flight sintering of size classified aerosols, J. Appl. Phys. 91 (2002) 2315-2321.

[50] A.M. Glazer, The classification of tilted octahedra in perovskites, Acta Crystallogr. B 28 (1972) 3384-3392.

[51] A.M. Glazer, Simple ways of determining perovskite structures, Acta Crystallogr. A 31 (1975) 756-762.

[52] C.J. Cheng, D. Kan, S.H. Lim, W.R. McKenzie, P.R. Munroe, L.G. Salamanca-Riba, R.L. Withers, I. Takeuchi, V. Nagarajan, Structural transitions and complex domain structures across a ferroelectric-to-antiferroelectric phase boundary in epitaxial Sm-doped $\mathrm{BiFeO}_{3}$ thin films, Phys. Rev. B 80 (2009) 014109 (11pp).

[53] Z. Ghorannevis, E. Akbarnejad, M. Ghoranneviss, Structural and morphological properties of ITO thin films grown by magnetron sputtering, J. Theor. Appl. Phys. 9 (2015) 285-290.

[54] C.S. Tu, C.M. Hung, V.H. Schmidt, R.R. Chien, M.D. Jiang, J. Anthoninappen, The origin of photovoltaic responses in $\mathrm{BiFeO}_{3}$ multiferroic ceramics, J. Phys. Condens. Matter 24 (2012) 495902 (5pp)

[55] W. Shockley, H.J. Queisser, Detailed balance limit of efficiency of p-n junction solar cells, J. Appl. Phys. 32 (1961) 510-519.

[56] H. Kim, C.M. Gilmore, A. Piqué, J.S. Horwitz, H. Mattoussi, H. Murata, Z.H. Kafafi, D.B. Chrisey, Electrical, optical, and structural properties of indium-tin-oxide thin films for organic light-emitting devices, J. Appl. Phys. 86 (1999) 6451-6461.

[57] A. Balasubramanian, M. Radhakrishnan, C. Balasubramanian, Dielectric behavior of amorphous indium oxide thin films, Thin Solid Films 193-194 (1990) 981-989.

[58] F. Zhang, W. Ma, H. Gao, Y. Zhao, X. Shan, K. Jin, H. Tian, Q. Zhao, D. Yu, X. Lu, G. Lu, S. Meng, Interfacial oxygen vacancies as a potential cause of hysteresis in perovskite solar cells, Chem. Mater. 28 (2016) 802-812.

[59] P.S.V. Mocherla, C. Karthik, R. Ubic, M.S.R. Rao, C. Sudakar, Tunable bandgap in $\mathrm{BiFeO}_{3}$ nanoparticles: the role of microstrain and oxygen defects, Appl. Phys. Lett. 103 (2013) 022910 (5pp).

[60] J. Seidel, D. Fu, S.Y. Yang, E. Alarcón-Lladó, J. Wu, R. Ramesh, J.W. Ager III, Efficient photovoltaic current generation at ferroelectric domain walls, Phys. Rev. Lett. 107 (2011) 126805 (4pp).

[61] R. Nechache, C. Harnagea, S. Licoccia, E. Traversa, A. Ruediger, A. Pignolet, F. Rosei, Photovoltaic properties of $\mathrm{Bi}_{2} \mathrm{FeCrO}_{6}$ thin films, Appl. Phys. Lett. 98 (2011) 202902 (3pp)

[62] R. Gao, C. Fu, W. Cai, G. Chen, X. Deng, X. Cao, Thickness dependence of photovoltaic effect in $\mathrm{BiFeO}_{3}$ thin films based on asymmetric structures, J. Electron. Mater. 46 (2017) 2373-2378.

[63] F. Yan, G. Xing, R. Wang, L. LI, Tailoring surface phase transition and magnetic behaviors in $\mathrm{BiFeO}_{3}$ via doping engineering, Sci. Rep. 5 (2015) 9128 (7pp).

[64] T.H. Wang, C.S. Tu, Y. Ding, T.C. Lin, C.S. Ku, W.C. Yung, H.H. Yu, K.T. Wu, Y.D. Yao, H.Y. Lee, Phase transition and ferroelectric properties of $x \mathrm{BiFeO}_{3}-(1-$ x) $\mathrm{BaTiO}_{3}$ ceramics, Curr. Appl. Phys. 11 (2011) S240-S243. 